\title{
Non-conventional Covid treatment methods 19
}

\begin{abstract}
In bioelectronic terms, the organism is understood as an integrated circuit of biological piezo, pyroelectrics, ferromagnets and semiconductors, filled with bioplasm and managed electronically by quantum processes. The presence of semiconductors in a biological system is synonymous with the presence of an electronic integrated device, therefore a living organism can be seen as a complex electronic device, analogous to technical devices. Proteins, DNA, RNA, melanin from the biology side, it is a biological structure, from the biochemistry side, they are chemical compounds with different chemical formulas, again from the bioelectronics side it is an electronic material that can serve as structural elements in a bioelectronic device which is an organism. Enzyme transistors were constructed in technical devices from these materials.
\end{abstract}

Keywords: pyroelectricity, piezoelectricity, Covid 19, bee products, enzymes
Volume 6 Issue 2 - 2021

\author{
Adam Adamski \\ University of Silesia in Katowice, Faculty of Ethnology and \\ Educational Science in Cieszyn, Poland
}

\begin{abstract}
Correspondence: Adam Adamski, University of Silesia in Katowice, Faculty of Ethnology and Educational Science in Cieszyn, Poland, Email a_adamski@o2.pl
\end{abstract}

Received: January 12, 2021 | Published: April 08, 2021

\section{Piezoelectricity in the human biological system}

The essence of the biological system includes piezoelectricity and pyroelectricity and semiconductivity. Piezoelectrics can convert mechanical energy into electrical energy and vice versa. A pulsating electric field applied to the piezoelectric causes its restriction, generating a quantum acoustic wave of the same frequency as the electric field. Some piezoelectric crystals are characterized by a constant polarity, even when there is no external interaction. Such crystals are called pyroelectrics. The ability of piezoelectric crystals to polarize at the expense of mechanical interactions and the ability to deform at the expense of applied electric fields allow them to be considered as electromechanical converters. ${ }^{2}$ In biological sciences, the piezoelectric phenomenon is assigned a significant role in the functioning of many biological tissues. Yasuda discovered ${ }^{3}$ the presence of piezoelectric polarization during compression of bones. Fukada, $\mathrm{Ueda}^{4}$ also investigated the piezoelectric effect in muscles - in actin and myosin fiber. ${ }^{5}$

The humidity of the samples has a significant influence on the value of piezoelectric molecules. The effect of humidity was tested in collagen, keratin and DNA. ${ }^{6}$ In keratin and collagen, the value of piezoelectric modules decreases with increasing humidity. ${ }^{7}$ Giuzelsu et al. ${ }^{8}$ showed piezoelectricity for nerves, ${ }^{8}$ while Shamos for the intestine and other biological tissues. ${ }^{9}$ Giuzelsu et al. ${ }^{8}$ believe that the size of an action potential depends on the size of the stimulus acting on the membrane and its piezoelectric properties, again the piezoelectric effect on the amount of water, protein and fatty acids in the membrane. In a biological system, bioelectronic processes resulting from piezoelectricity are noticeable: mechanoreceptors, in the sense of temperature; the process of breathing. ${ }^{8}$ The process of fertilization of the egg during sexual arousal; - during the work of the intestines - peristaltic movements, in the blood circulation system; Piezoelectric, in order to be able to release electric charges in constant motion, must be excited by dynamic mechanical force. If the force is kept at one level, the electric potential is lost. ${ }^{10}$

\section{Pyroelectric properties of biological structures}

The pyroelectric phenomenon creates electric charges on the surface of dielectric crystals when they are heated or cooled. During heating, one end of the pyroelectric charge becomes positive, and the other - negative. ${ }^{11}$ The charge formation depends on the rate of temperature change. Fluctuating temperature creates a spontaneous polarization which leads to an alignment of dielectric charges in a certain direction, even when the external electric field is not working. All pyroelectric crystals are also piezoelectrics. ${ }^{12}$ Any mechanical deformation of a pyroelectric body changes its dipole moment and produces a piezoelectric effect. In pyroelectric crystals, the opposite phenomenon may also occur, which is the electrocaloric effect, consisting in the change of the pyroelectric temperature under the influence of the electric field. ${ }^{2}$ In 1966. Lang proved that collagen fibers exhibit pyroelectric properties. ${ }^{13}$ Athenstaedt proved that teeth, bones, tendons, collagen fibers and keratin exhibit pyroelectric and piezoelectric properties. ${ }^{14}$

Any change in temperature causes a change in the length of the pyroelectric body and changes its elementary dipole moments (this is the pyroelectric effect). In the same way, any mechanical deformation of a pyroelectric body causes a change in its dipole moment (it is a piezoelectric effect). ${ }^{15}$ The pyroelectric effect has been proven on the entire body surface of living animals and plants and is not limited to certain areas of the body surface, such as at the sensory receptor, where the skin in different areas has a different kind of feeling. ${ }^{16}$

In 1974, Liboff and Furst confirmed the pyroelectric effect in collagen and believe that it is responsible for the formation of protein structures. ${ }^{17}$ Pyroelectric properties play an important role in thermoreception. ${ }^{18}$ In biological cells, pyroelectricity and piezoelectricity play an important role in maintaining morphological polarity in the polar processes of cell division in mitosis and meiosis, in enzymatic and cellular communication. This field integrates the whole organism, regulates metabolic processes and directs the organism's growth. It records a perceptual impression not only in the brain, but also in the entire body, wherever there is protein, DNA, RNA. ${ }^{19}$ The change in light intensity also causes the pyroelectric phenomenon, because light absorption causes temperature changes in pyroelectric bodies. ${ }^{20}$

\section{Ferroelectricity of biological structures}

Ferroelectrics are bodies in which spontaneous polarization occurs in a certain temperature range in the absence of an external electric field. The direction of spontaneous polarization can be changed by the action of an external electric field and by external pressure. 
Ferroelectrics under the influence of an external electric field undergo deformation which is proportional to the square of the field strength. This phenomenon is called electrostriction. All ferroelectrics, apart from electrostriction, show a piezoelectric effect. ${ }^{10}$ In pyroelectrics, spontaneous polarization exists over the entire temperature range, up to the melting point. Ferroelectrics are a special case of pyroelectrics in which spontaneous polarization also occurs, but only over a certain temperature range. Research has shown that many biostructures have ferroelectric properties. ${ }^{21}$

\section{Action of enzymes based on piezoelectricity and pyroelectricity}

Our immune system cannot function without enzymes. Their job is to attack pathogens, remove toxins, and instantly utilize large numbers of used cells that are a potential source of poisons. Enzymes participate in the construction of all tissues, without enzymes blood production would be impossible. ${ }^{22}$ Enzymes are necessary for the digestion of food, the release of vitamins, ingredients minerals and amino acids. Enzymes absorb the electric field energy needed for their work and communication. ${ }^{23}$

Some enzymes are involved in the copying and expression of genetic information, they do it with a very high precision, show the ability to "correct". Modern enzymological diagnostics is based on the assumption that damage to an organ causes damage to cell structures or changes in the permeability of cell membranes. Damage to the membranes causes the escape of enzymes from cells, thus increasing their amount in body fluids and excretions, such as: blood, cerebrospinal fluid, urine, exuding and exuding fluids, gastric juice or duodenum. ${ }^{24}$ In viral and bacterial diseases, the activity and invasiveness of pathogens often depends on their activity or the host enzyme. The appropriate presence of selenium in the human biological system does not allow for mutations and is at the same time an essential element of the body's defense against influenza and other viruses. Fish, crustaceans, garlic, Brazil nuts and mushrooms are rich sources of selenium..$^{25}$ Enzyme drugs must be introduced to fight the coronavirus. In defense against cancer and viruses, enzymes are very important. This is supported by the fact that the coronavirus attacks the elderly more often, when the body produces fewer and fewer enzymes and they are less active. Civilization diet poor in enzymes and coenzymes sufficiently weakens the body and its defense mechanisms. A wholesome diet rich in salads and high melanin content, rich in enzymes and coenzymes effectively protects against coronavirus and other diseases. ${ }^{24}$

\section{Action of melanin in fighting covid I 9}

Melanin and neuromelanin play an important role in the fight against COVID 19 and are responsible for the central control of all biological, physiological and psychological processes. Raspberry is a sticky molecule. Bacteria, fungi and viruses are stuck together by it and stop multiplying. ${ }^{26}$ Melanin synthesis occurs under the influence of light, an electric field and thermal energy. In fall and winter, when the night is longer than the day, when the day is gloomy and there is no sun, melanin flows out of the human body and melatonin replaces melanin, changing life expectancy and the aging process. Melanin resources in the biological system are regulated by the sun and movement in summer, in autumn and winter there is less melanin, so it should be supplemented with a wide range of exercise, such as gymnastic exercises, walking, cycling, running, mountain hiking, dancing, music, etc. Movement is needed, because bone structures are piezoelectrics which, when influenced by movement, trigger an electric field that is needed for melanin synthesis. Melanin synthesis takes place not only by light path but also by piezoelectric or pyroelectric polarization. ${ }^{27}$

Apart from exercise, the diet should include vegetables and fruits that contain a large amount of melanin, such as dark fruits chokeberry, blueberry, cherry, cherry, elderberry, grapes, cranberry, blackberry, mountain ash, blueberry etc. ${ }^{28}$ Garlic, ginger, horseradish are effective in destroying the coronavirus. Children have greater amounts of melanin in the body than the elderly, so their incidence of COVID 19 is very low. High susceptibility to catching COVID 19 occurs in children who have complications with chronic diseases of the throat, lungs, or are in the process of treating other diseases. Sunbathing and sunbathing have a significant impact on the growth of melanin in the human biological system. Research has shown that fair-skinned people are more prone to catching COVID 19 than darkskinned individuals. ${ }^{29}$ Failure to use the sun leads to the development of a pandemic, it can be seen among miners.

\section{The role of bose-Einstein condensate in limiting the development of covid I9}

According to Jibu and Yasue, Bose-Einstein condensates are located inside and outside of the neuronal membrane and can combine to form the so-called Josephson anastomosis. The potentials of the biological membrane of the cell induce self-excited oscillations and stimulate the Josephson junction to produce solitons along the biological membrane. Soliton waves retain their form over long distances and can propagate to macroscopic dimensions, which may turn out that cellular conductivity transmits information via the ion and soliton route..$^{30}$ Pouget and Maugina showed the action of solitons in ferroelectrics, along with electroacoustic interaction which is conditioned by the piezoelectric effect and electrostriction. The movement of solitons is influenced by the density and thickness of the biological membrane in the cell, as it determines the size of the piezoelectric effect from which the electric field flows, interacting with solitons. ${ }^{31,32}$

Solitons are formed in nonlinear optical centers and in BoseEinstein concentrates. Strong laser waves, degree of nonlinearity, and high concentration of atoms in Bose-Einstein condensates have an influence on the formation of multidimensional solitons. Currently, the highest degree of non-linearity is achieved by organic substances in which electrons have the ability to travel long distances. ${ }^{33}$ Soliton is a solitary wave of unchanging shape, located in time and space. It reaches a constant value at infinity, it can interact with other solitons, but after a collision it remains unchanged, only a phase shift occurs. In the Bose-Einstein condensate, quantum processes show a high order and a high degree of unity. This means that the entire object has one constant phase. More figuratively speaking, one human's biological system synchronizes with another organism and operates in a single phase, which is about the common biological field for both organisms. A strong common idea, thought, and attention influences the formation of solitons through Bose-Einstin condensate, which trigger one phase of the biological field of bioplasma, eliminating the effect of COVIDA19. ${ }^{34}$ If you want to be in a group, choose one with deep prayer or meditation as they create a Bose-Einstein condensate that creates a common biological field for the whole group. The author's study shows that high religiosity in individual groups or church parishes is a low rate of coronavirus infections.

\section{COVID I 9 does not like jumps in temperature difference}

The jump in the temperature difference for a biological system is related to the change in the electric field in pyroelectrics and 
ferroelectrics. The change in temperature causes an electric field to be different for the host cell and for the coronavirus. The difference in the electric field informs the biological cell that there is a foreign body on its surface, which operates in a different information and management system than the host organism. This difference in electric field stimulates the body to produce enzymes that destroy the coronavirus. Methods of applying temperature jumps and piezoelectric actions Temperature jump during bathing. We run hot water and suddenly cold water. We do it on alternating. - Water showers, known as Scottish showers. Scottish shower is a procedure that stimulates the body with jets of water with variable pressure and temperature. These strong stimuli stimulate circulation and help fight COVID 19. Consult a doctor before performing the treatment, as water jets have many contraindications. - Finnish sauna or dry sauna. The air temperature in it reaches from 60 to 110 degrees Celsius while maintaining the humidity at the level of $5-15 \%$. The very high temperature in the dry sauna makes sauna users more likely to use its steam version, which is slightly cooler. Regular visits to a dry sauna can bring us many benefits. Staying in a dry sauna cleanses the body of toxins. It is also a good method to relax and unwind. relieving the tension resulting from stress and removing the coronavirus from the body. Coronavirus does not develop when air circulation is present. We ventilate the air with fans. We try to ventilate our apartments frequently. In shops and in various institutions there should be hot and cold air blowers for ventilating the rooms. ${ }^{28}$

COVID 19 dies at 65 degrees Celsius - we organize bonfire meetings. We do games for children and teenagers, and the elderly by the fire. The temperature around the fire is from $100-800$ degrees $\mathrm{C}$ and more. This temperature reduces the overall viability of the coronavirus throughout the human body and disinfects clothes. There is no possibility of a droplet infection with coronavirus, because such high temperature will destroy it immediately. In villages we burn fires in natural conditions, again in cities there should be a basket with a fire on the streets, or devices emitting high temperature, so that a person can stay for 2 or 5 minutes and warm the body, while disinfecting his clothes and body.

\section{Highly alkaline products in combating COVID 19}

The $\mathrm{pH}$ of the coronavirus ranges from 5.5 to 8.5 , to eliminate the coronavirus, you should eat more alkaline food. Strongly alkaline products from 8.5 to 9.0 Lettuce, pineapple, watermelon, beetroot, zucchini, lemons, grapefruit, kiwi, cucumber, papaya, rhubarb, raisins, dried figs and apricots, spinach, seaweed, potatoes, alkaline water. Alkaline products from 7.5 to 8.5 Onions, garlic, horseradish, and apples. Blueberry, carrot, cauliflower, mandarins, natural milk, parsley, celery, tomatoes, orange, mushrooms, fresh ginger, strawberries, grapes, gooseberries, bananas, beans. Human saliva has a $\mathrm{pH}$ of 6.5 to 74 , and blood has a $\mathrm{pH}$ of 7.35 to 7.45.). ${ }^{22}$ Zinc deficiency is manifested primarily by reduced immunity. If you have a frequent cold, it is very possible that it is due to a lack of zinc in your body. The coronavirus likes to attack the biological membranes of the sense of taste and smell, leading to impaired sense functions. This is due to the lack of zinc in the body. Zinc resources in vegetables: tomato - 11 units of calculation, parsley - 13 , cabbage - 16 , cocoa - 17 , beans -23 , wild rice -38 , linseed -28 , sesame -29 , wheat germ -31 . pumpkin seeds - 33 , chanterelles - 36 , mushrooms - 36, adzuki beans - 36, oyster mushrooms - 48. Fish, crustaceans, garlic, Brazil nuts and mushrooms are rich sources of selenium. ${ }^{25}$ Garlic, ginger, horseradish are effective in destroying the coronavirus.

\section{Apiculture products are a valuable remedy for the coronavirus}

Propolis, royal jelly contains large amounts of enzymes, pollen, honey, but also tinctures and larch juice, as well as fruits and vegetables containing large amounts of melanin. At every stage of the disease, the patient should be in motion, use active body massage. Artificial respiration should be used because it activates the alveoli, which, as mechanoreceptors, polarize the protein structures in the alveoli and release the electric field that directs the respiration process. We use a mixture of honey (linden, honeydew, buckwheat - honey of your choice) with propolis, flower pollen or royal jelly, and amber tincture. Grind the pollen in a mortar to reach the nucleus as the most valuable protein is there. We put a dozen or so drops of propolis per tablespoon of honey and amber tincture. ${ }^{28}$

\section{Pine syrup plays an important role in the treatment of coronavirus}

In laboratory conditions, it has a strong antibacterial, antifungal and antiviral effect. Pine oil and syrup have an expectorant effect and dissolve phlegm, being a natural support in infections of the upper respiratory tract with runny nose and cough. In combination with eucalyptus oil, it perfectly unplugs a blocked nose. Terpineol, which is a terpene, has been found in the flowers of pine, elderberry, eucalyptus and linden. It has anti-inflammatory, analgesic, antifungal, antiviral and antioxidant properties, it is able to relax smooth muscles, which makes it a valuable remedy for asthma. ${ }^{35}$ Alpha-pinene is responsible for the aroma of fresh pine needles, conifers and sage. Juniper berries are also a source of alpha pinene. It is also produced by many herbs such as parsley, rosemary, basil, and dill. It is the most common terpene in nature Amber, i.e. the resin of some pine species that have been fossilized for centuries. It is believed that spirit tincture on amber strengthens immunity, alleviates the symptoms of colds, runny nose, fever, as well as rheumatic and muscle pain. ${ }^{36}$ Ginger has been used for centuries as a remedy for colds and runny nose. The chemical compounds of ginger increase the body's resistance - we get sick less often. Ginger perfectly cleans the microcirculation system, including the sinuses, which can be felt during colds and flu. Ginger root is antiinflammatory, antiviral and antibacterial. Powdered ginger has no such effect. Ginger also has warming properties, which is crucial in colds, as it supports the natural cleansing of the body through sweating. ${ }^{37}$ We come into contact with nature a lot, we don't wear masks, only in situations that force us to do so. Face masks are a contributing factor to the pandemic.

Such an employee touches the face mask during work, our food products and there is a social development of the pandemic. In addition, there is emphysema, who will treat it after the epidemic. Place the purchased food products in an electric oven at temperature for 1-3 minutes 100 degrees C. Coronavirus dies at 65 degrees. School children, soldiers and students should not wear face masks. In schools, students create a common biological field phase for the entire building that protects against COVID 19. Diagnosing patients with Kirlian photography - this camera records biological electrostasis and can be a test to diagnose coronavirus in patients. It is known in science and may be useful in medicine. Duration of contamination of objects and surfaces, the study showed that SARS-CoV-2 can be found on plastic up to 2-3 days, stainless steel up to 2-3 days, cardboard up to 1 day, copper up to 4 hours. In addition, contamination appears to be greater in intensive care units (ICUs) than in general departments, and SARSCov-2 can be found on floors, computer mice, trash cans, and patient rails, as well as in the air at distances up to 4 meters from patients. ${ }^{35}$ 


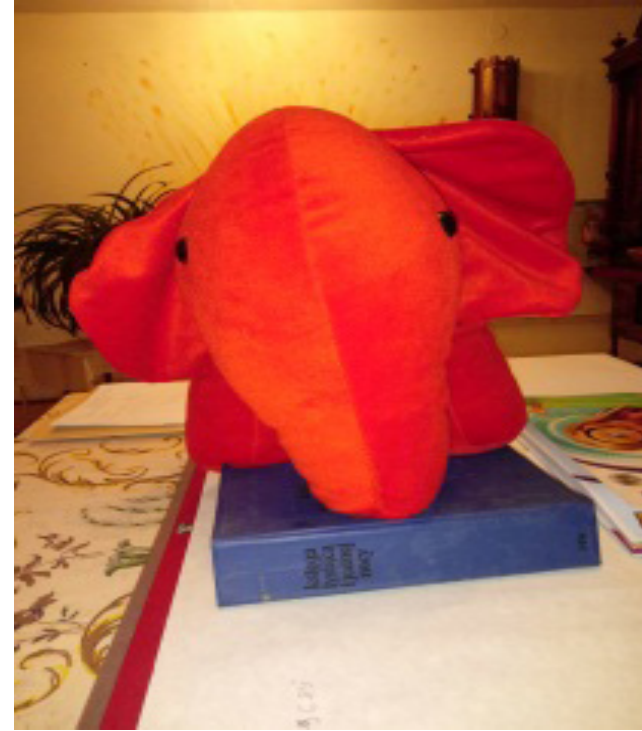

Figure I 2,3,4 shows the worker behind a counter with a mask.

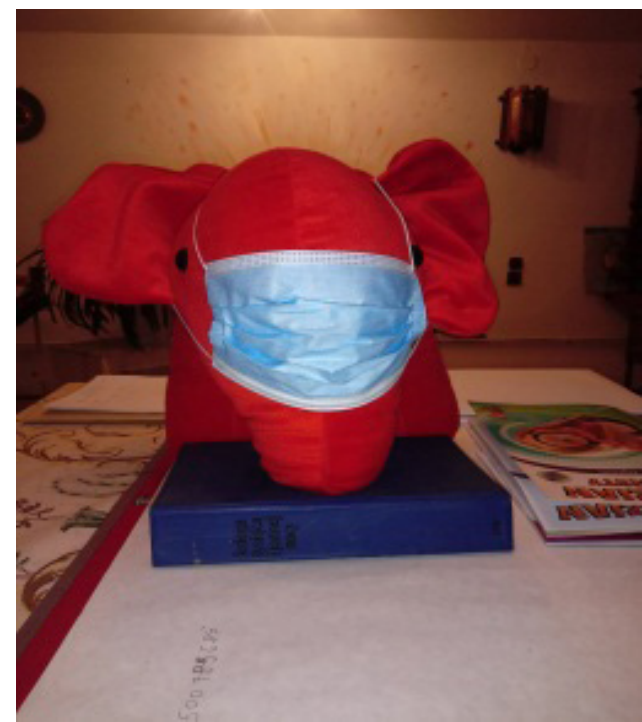

Figure 2 Employee when starting work.

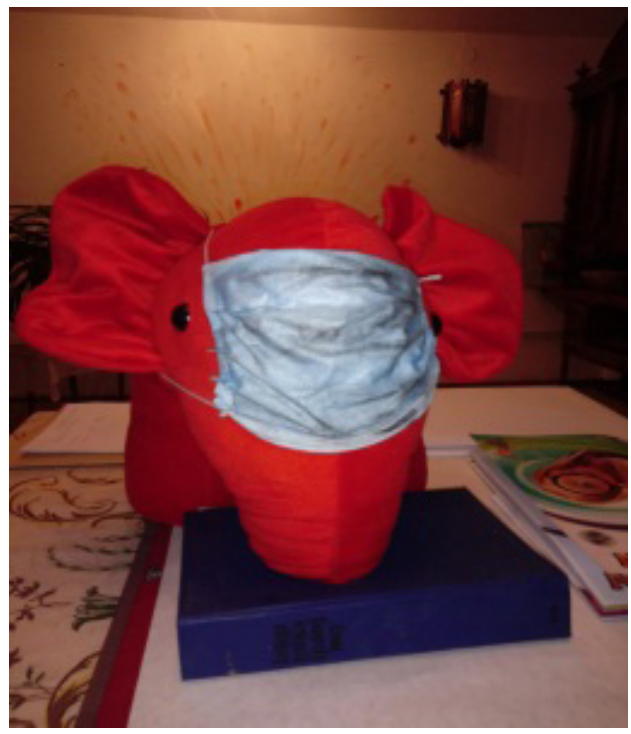

Figure 3 Employee after 3 hours of work.

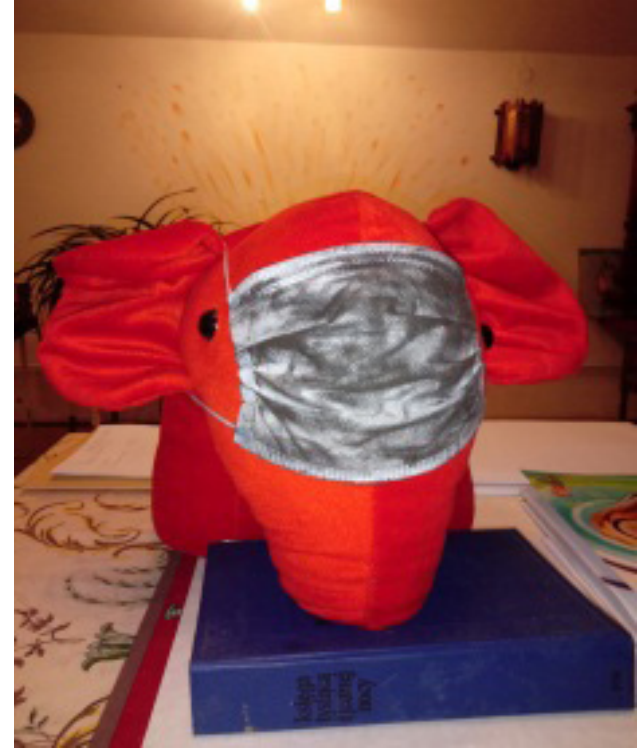

Figure 4 Eemployee after 6 hours of work.

\section{Conclusions}

The focus should be on the development of new health and nutrition programs, methods of recreation, sports, recreation, organization of cultural and educational events in the information environment. Prevention of pathological mechanisms of human behavior during a pandemic. Prevention of mental disorders resulting from a pandemic. ${ }^{38-40}$ Development of treatment programs with bee products and herbal medicine $\mathrm{WHO}$ and other organizations have made the following general recommendations:

i. Avoid close contact with people suffering from acute respiratory infections.

ii. Wash your hands often, especially after coming into contact with infected people or their environment.

iii. Avoid unprotected contact with farmed or wild animals.

iv. People with symptoms of acute respiratory infection should keep their distance, cover their face when coughing or sneezing, and wash their hands.

v. Strengthening, especially in emergency departments, the application of stringent hygiene measures to prevent and control infections.

vi. Immuno compromised people should avoid public gatherings.

\section{Acknowledgments}

None.

\section{Conflicts of interest}

None.

\section{Funding}

None.

\section{References}

1. Cardenas ML. Are the transistors enzyme - complexes found in vitro also transistors in vivo? If so, are they physiologically important. Journal of Theoretical Biology. 1991;152(1991):111-113. 
2. Kleszczewski Z. Fizyka kwantowa, atomowa i ciała stałego. Gliwice. Wydawnictwo Politechnika Śląska. 1997.

3. Soluch W. Wstęp do piezoelektroniki. Wydawnictwo Komunikacji i Łączności. Warszawa. 1980.

4. Fukada E. Ueda H. Piezoelectric effect in fibrin films. Reports on Progress in Polymers Physics. 1971;14:482-484.

5. Fukada E. Piezoelectric effect in muscle. Jap Reportes on Progress. in Polymers Physics in Japan, Journal of Applied. Physics. 1970;9:844-849.

6. Fukada E. Ando I. Piezoelectricity in oriented DNA films. Journal of Polymer Science. Part A: Polymer Chemistry. 1972;210:565-567.

7. Fukada E. Piezoelectric properties of biological macromolecules. Advanes in Biophysics. 1974;6:121-125.

8. Giuzelsu AN, Akcasu A. A Piezoelectric model for nerve conduction Annals of the New York Academy of Sciences. 1974;238:239-249.

9. Shimomura M. Electronic communications between molecular associates and enzymes. Kagaku Kyoto. 1991;46(8):571-576.

10. Kawai H. Electrostriction and piezoelectricity of elongated polymers films. Oyo Buturi. 1970;39:413-419.

11. Shamos MH, Lavine L. Piezoelectricity as a fundamental propertis of biological tissues. Nature. 1967;213(5073):267-269.

12. Chełkowski A. Fizyka dielektryków. Warszawa: PW. 1979.

13. Krajewski T. Zagadnienie fizyki dielektryków. Warszawa, PWN. 1970

14. Athenstaedt H. Pyroelectric and piezoelectric properties of vertebrates. Annals New York Academy of Sciences. 1974;238:69-94.

15. Athenstaedt H, Claussen H, Schaper P. Epidermis of human skin: Pyroelectric and piezoelectric sensor layer. Science. 1982;216(4549):10181020.

16. Athenstaedt H. Spontaneous polarization and pyroelectric behavior of organisms. Ferroelectrics. 1987;73(1):455-466.

17. Lebrun I, Marques-Porto R, Pereira A, et al. Bacterial toxins: an overview on bacterial proteases and their action as virulence factors. Mini Rev Med Chem. 2009;9(7):820-828.

18. Cope FW. Solid state physical mechanism of biological energy transduction. Annals of the New York Academy of Sciences. 1974;227:636640 .

19. Pouget J, Maugin G. Solitons and electroacoustic interactions in ferroelectric crystals. Interactions of solitons and radiations. Physical Review B. 1985;31(7):4633-4649.

20. Athenstaedt H. Pyroelectric behaviour of integument structures and of thermo, photo and mechanoreceptors. Zeitschrift fiir Anatomie und Entwicklungsgescichte. 1972;136(3):249-271.

21. Leibold G. Enzymy lekarstwo przyszłości . Warszawa Wydawnictwo. SPAR. 2000

22. Nieumywakin I. Bursztyn na straży zdrowia. Wydawnictwo. Vital . Łódz. 2019
23. Sedlak W. Bioelektronika 1967-1977. Warszawa IW PAX. 1979.

24. Liboff AR. Furst M. Pyroelectric effect in collagenous structures. Annals of The New York. Academy of Sciences. 1974;238(1):26-36.

25. Lang SB. Pyroelectric effect in bone and tendon. Nature. 1966;212:704 705.

26. Leuchtag R. Fit of the dielectric anomaly of squid axon membrane near heat-block temperature to the ferroelectric Curie-Weiss law. Biophysical Chemistry. 1995;53(3):197-205.

27. Adamski A. Melanina, enzymy, melatonina w zdrowiu i chorobie. Rybnik: Wydawnictwo. Magnum. 2005.

28. Adamski A. Quantum nature of coronavirus and method of treatment. Neurology. 2020;12(12):135-150.

29. Karthick R, Meenalochini P, Sheik Dawood M, et al. A Geographical Review: Novel Coronavirus (COVID-19) Pandemic.Asian. Journal of Applied Science and Technology (AJAST) (Quarterly International Journal).2020;4(2):44-50.

30. Jibu, M. Yasue K. Magic withoust magic. Meaning of quantum brain dynamics. The Journal of Mind and Behavior. 2000;2(3):205-228.

31. Pleś M. Enzymy biologiczne katalizatory Chemia w Szkole, Agencja AS Józef Szewczyk. 2016:6-11.

32. Pouget J, Maugin GA. Solitons and electroacoustic interactions in ferroelectric crystals. I Single solitons and domain walls. Physical Review B. 1984;30(9):5306.

33. Brizhik, L. Influence of electromagnetic field on soliton mediated charge transport in biological systems. Electromagn Biol Med. 2015;34(2):123132.

34. Adamski A. Role of Bose-Einstein condensate and bioplasma in shaping consciousness. NeuroQuantology. 2016;14(1):896-907.

35. Baron EP. Medicinal Properties of Cannabinoids, Terpenes, and Flavonoids in Cannabis, and Benefits in Migraine, Headache, and Pain: An Update on Current Evidence and Cannabis Science. Headache: The Journal of Head and Face Pain 2018;58(7):1139-1186.

36. Nartowska J. Imbir lekarski. Panacea. 2008;3(24).

37. Mackintosh JA, Trimble JE, Jones MK, et al. Antimicrobial mode of action of secretions from the metapleural gland of Myrmecia gulosa (Australian bull ant). Canadian Journal of Microbiology. 1995;41:136-144.

38. Adamski A. Układ biologiczny, jako urządzenie elektroniczne w poznawaniu środowiska i samego siebie. Praca zbiorowa pod red. Adama Adamskiego. Człowiek - jego bioelektroniczna konstrukcja a percepcja muzyki. Wyd. Drukarnia Propak Kęty. 2006.

39. Adamski A. Rola procesów bioelektronicznych w kształtowaniu percepcji zmysłowej i funkcji psychicznych człowieka. Katowice. Wydawnictwo Uniwersytet Śląski w Katowicach. 2006.

40. Yasuda L. On the piezoelectric activity of bone. Central Journal of the Japanese Orthopaedic. Surgery Society. 1954;28:267-269. 